\title{
Congreso Internacional Cesare Pavese. Un clásico del siglo XX. En el centenario de su nacimiento (1908-2008)
}

\section{Del 27 al 31 de octubre de 2008.}

Facultad de Filología. Universidad Complutense de Madrid

\section{Elisa Martínez Garrido}

Universidad Complutense de Madrid elimarti@filol.ucm.es

Con ocasión del centenario del nacimiento de Cesare Pavese (16- 9- 1908), el Departamento de Filología Italiana de la Facultad de Filología de la Universidad Complutense de Madrid, en unión a la Fondazione Cesare Pavese de Santo Stefano Belbo y al Instituto Italiano de Cultura de Madrid, ha dedicado al escritor piamontés una semana de estudios, mediante un importante Congreso Internacional que ha reunido a un gran número de pavesistas italianos y europeos.

La Complutense de Madrid se ha sumado así al rosario de actos culturales organizados en todo el mundo para la celebración del nacimiento del gran escritor de Las Langas. El Congreso de Madrid ha tenido la particularidad de haber contado, como sede internacional de primer orden, con el apoyo institucional de la Fondazione Cesare Pavese, a través de su Director Científico, Franco Vaccaneo y de su Presidente, el Profesor Elio Gioanola.

Nuestro Congreso ha sido un congreso realmente excepcional. Nombres como el de Elio Gioanola (Universidad de Génova), Giorgio Barbèri-Squarotti (Universidad de Turín), Gian Luigi Beccaria (Universidad de Turín), Fausto Curi (Universidad de Bolonia) o Lorenzo Mondo (periodista y escritor) nos hablan del nivel de excepción de la semana dedicada a Pavese en Madrid, ya que nos encontramos ante algunas de las figuras críticas más importantes de la escuela italiana de la segunda mitad del recién clausurado siglo XX. Al pronunciar estos nombres, los italianistas reconocemos a nuestros maestros, a los grandes profesores y a los grandes críticos, quienes, sobre la obra de Cesare Pavese y sobre la obra de los grandes autores de la literatura italiana del siglo XX (y de otros periodos históricos) han abierto "paradigma científico»; sus ensayos han servido para toda una generación (en la que estoy incluida) y seguirán dando luz en el camino de la exégesis y de la hermenéutica del texto literario escrito en lengua italiana.

En estos días del otoño pasado, estos respetados y admirados colegas (es para mí un enorme honor poder usar para con ellos tal palabra), al hablarnos del Pavese más leopardiano, a la búsqueda del salto en el vacío psicológico y del silencio del que emana la poesía, La strada del salto nel vuoto de Elio Gioa- 
nola, de la importancia que comporta el mismo final trágico y suicida del escritor, con su consiguiente entrada existencial, de pleno derecho, en el terreno de lo irracional-mítico, Dialogo con se stesso e Dialoghi con Leucò de Giorgio Barbèri-Squarotti, de la fuerza y de la belleza de la lengua pavesiana en su novela La luna e i falò, modelada sobre los hitos de la alta tradición literaria italiana, de Gian Luigi Beccaria, o de la fuerza renovadora y subversiva del elemento popular y realista de Lavorare stanca, en el caso de Fausto Curi, nos han devuelto el mismo idéntico e intenso placer intelectual que ya nos habían aportado con sus grandes textos críticos; un placer ahora incluso renovado por la cercanía personal de la voz y la palabra.

Somos conscientes de la importancia que la aportación de estas ilustres figuras del italianismo internacional ha representado para nuestro Congreso, y del peso que sus escritos otorgará a la futura publicación de las Actas, a cargo de la Fondazione Cesare Pavese, dirigida por Franco Vaccaneo.

En la semana pavesiana de la Complutense hemos contado también con la presencia de otros no menos importantes y prestigiosos colegas, provenientes del italianismo italiano y europeo: Giovanna Ioli de la Universidad de Turín, con su Pavese e la lezione dantesca, Elisabetta Soletti, de la misma Universidad, con Parole e paesaggio: le colline di Pavese, Marco Bazzochi, de la Universidad de Bolonia, con su Il palude di sangue: il pensiero tragico di Cesare Pavese, Arnaldo Bruni, de Florencia, con Pavese contro corrente: Dialoghi con Leucò, Francesco Muzzoli, de La Sapienza de Roma, Dialettica del mito nei Dialoghi con Leucò y Bart Van den Bossche de la Universidad de Lovaina y su Cesare Pavese e il macrotesto: da Lavorare stanca a Feria d'agosto e a Dialoghi con Leucò. Las comunicaciones de estos queridos colegas han vuelto a situarnos ante un quehacer crítico filológico y renovado a su vez, gracias a las consideraciones críticas de las nuevas metodologías. Ellos han dado una vez más lo mejor de sí mismos, con una óptica más renovadora y ajustada a las necesidades de una exégesis clásica.

La riqueza del Congreso residió no solo en la presencia y en las aportaciones de los colegas venidos de Italia y de Europa, sino en el contrapunto que ofreció la mirada de los italianistas españoles y la de los colegas y compañeros de la Facultad de Filología provenientes de otros Departamentos, quienes como especialistas en otras literaturas contemporáneas ofrecieron una visión contrastiva muy interesante de la obra del escritor langarolo.

Entre los italianistas españoles, contamos con la presencia de José Abad Baena de la Universidad de Granada: La poesía de Cesare Pavese según la Antología de José agustín Goytisolo, con Giovanni Albertocchi de la Universidad de Girona: Il sistema della memoria ne la Luna e i falò, María José Calvo Montoro de laUniversidad de Castilla-La Mancha, Cesare Pavese en los orígines de la escritura de Italo Calvino, Elisa Martínez Garrido de la UCM, La potencia visual de La luna y las hogueras, José Manuel Muñoz Rivas de la Universidad de Extremadura, Edgars Lee Masters en la teorización Poética de Pavese y Rosario Scrimieri Martín también de la UCM, Cesare Pavese y la tradición poética del simbolismo italiano. 
Los colegas procedentes de los demás Departamentos de la Facultad de Filología de la UCM (Clásicas, Francesa, Románica, Inglesa, Alemana, Portuguesa y Hebrea) ofrecieron una aportación que ayudará sin duda a conocer mejor el intertexto pavesiano, sobre todo en el caso de la literatura clásica y angloamericana. Contamos con los nombres de Javier Del Prado Biezma, Poeticidad y narratividad en la organización del poema pavesiano, Javier Fernández Vallina, El peso de la "memoria» histórica en La Luna y las hogueras, Carlos García Gual, Viajando sobre el velo de Leucótea, Arno Gimber, La recepción de Cesare Pavese en Alemania, Dámaso López García, El apéndice inglés de la literatura norteamericana. Preocupaciones de Cesare Pavese, José Manuel Lucía Megías, Pavese antes de Pavese, una cuestión de crítica genética, Félix Martín, Cesare Pavese: ¿en busca de la América primigenia?, Eugenia Popeanga, Espacios fundamentales en Cesare Pavese y Esther Sánchez Pardo, El americanismo de Pavese: traducción, estética e ideología. A estas sesiones se sumó también la voz del amigo escritor Miguel Naveros, ex alumno de la UCM y Director del Centro de Estudios Almerienses, Mi último salto en el vacío: Cesare Pavese.

El último día del Congreso se dedicó a las comunicaciones de los jóvenes investigadores. En esta jornada, una de las más interesantes tanto por el alto nivel de las exposiciones como por la variedad de argumentos que en ella se expusieron, contamos con la presencia de estudiantes de postgrado, master y doctorado provenientes de varias Universidades europeas: Claudia Bussolino de la Universidad de Pavía, Edmundo Condon UCM, Cristina Coriasso UCM, Fabrizio Cossalter de la Universidad de Padua, Víctor Granado UCM, Rocío Peñalta UCM, Margherita Quaglino de la Universidad de Siena, Franca Roverselli UCM, Inés Valle UCM y Leonardo Vilei, Universidad de Turín-UCM.

En las tardes del Congreso se realizaron diversas actividades culturales, unas en el Instituto Italiano de Cultura de Madrid y otras en la Facultad de Geografía e Historia y en la Facultad de Filología. La tarde del 27 tuvo lugar en el Instituto Italiano de Cultura una mesa redonda dedicada a Cesare Pavese y su presencia en las letras hispánicas. En ella estuvieron presentes editores, intelectuales y escritores españoles, italianos y latinoamericanos: Fany Rubio, Luis Mateo Díez, Marta Rivera, Luís Matamoro, Manuel Ramírez y Silvia Querini. Las tardes del 28 y del 29 de octubre se dedicaron a la proyección de películas dedicadas a la vida, a los amigos y a los lugares pavesianos. Se trata de trabajos cinematográficos realizados por la Fondazione Cesare Pavese de Santo Stefano Belbo: Un paese ci vuole de Vanni Vallino, Un ritratto di Pavese de Andrea Icardi y Viaggio nei luoghi di Cesare Pavese de Claudio Dezani.

Desafortunadamente, por razones de enfermedad propia o de los más cercanos, algunas ilustres voces que figuraban en el programa del Congreso no pudieron estar con nosotros durante estos días. Esperamos contar, sin embargo, con sus aportaciones en las Actas que ya están empezando a ponerse en marcha.

Para cerrar, solo queda decir que el Congreso fue un éxito, la prensa nacional y local se hizo eco del evento, y entre la comunidad universitaria y entre los italianistas podemos decir que gozamos de una semana de gran estímulo 
intelectual en torno a una de las figuras más importantes de la Literatura Universal contemporánea: Cesare Pavese. El escritor de Las Langas es, sin algún lugar a dudas, un clásico del siglo XX y un mito cultural de nuestra sociedad.

Queda ahora por llevar a cabo quizás la labor más importante del Congreso, la publicación de las Actas. Se dejará así testimonio vivo y escrito de las jornadas intensas de Madrid, ricas en poesía, en saber, en conocimiento y en pasión. Esperamos que las Actas del Congreso de Madrid 2008, si no logran tener el peso de la fulgurante aparición de la revista Sigma de 1964, dedicada por entero a la escritura de Cesare Pavese, sean, al menos, un importante punto de referencia en la profundización crítica del gran escritor piamontés. Esperamos que así sea, que entre todos seamos capaces de alcanzar nuestra meta. 